\title{
The Differences requency of Lower Extremities Muscle Strength and Functional Capacity on the difference Supervised Exercise Frequency in Post Cardiac Bypass Graft Surgery
}

\author{
Dewi Nur Fiana ${ }^{1}$, Sunaryo B Sastradimaja ${ }^{1}$, Badai Bhatara Tiksnadi²
}

1. Department of Physical Medicine and Rehabilitation, University of Padjadjaran Bandung, Indonesia.

2. Department Of Cardiology And Vascular Medicine Medical Faculty, University of Padjadjaran

\begin{abstract}
Introduction: The optimal time to do exercise in adaptation phase was 36 to 72 hours. Patients with cardiovascular disease may have an extended adaptation phase to 96 hours and above. It was necessary to know the most effective supervised exercise in phase II cardiac rehabilitation between three times/week for 36-hours, and two times/week for 96-hours.
\end{abstract}

Method: This study involved 30 patients post-Cardiac Bypass Graft Surgery (CABG) participated in phase II cardiac rehabilitation at Hasan Sadikin Hospital, Bandung. Subjects divided into two groups; that have done two times/week (group 1) and three times/week of the supervised exercised (group 2) for four weeks. The Lower extremity muscle strength (LEMS) examined by conducting a chair standing test, while functional capacity (FC) evaluated by the 6-minute walking test.

Result:Subjects were 58,54 $\pm 5,90$ y.o (group 1) and 61,66 $\pm 6,36$ (group 2). The FC and the LEMS before and after exercise were 10,98 and $15,96 \mathrm{ml} / \mathrm{kg}(<0,001)$ on the $\mathrm{FC} ; 7,8$ and 12,9 times $(<0,001)$ on the LEMS in group 1 , besides 9,6 and $14,9 \mathrm{ml} / \mathrm{kg}(<0,001)$ on the $\mathrm{FC} ; 8,7$ and 13,0 times $(<0,001)$ on group 2 ,

Conclusion. Both groups have increased of the FC and the LEMS after exercise. There were no difference between 2 times and 3 times of supervised exercises a week on post CABG pasients

Keywords: coronary artery bypass graft, the frequency of exercise, functional capacity, muscle strength =

\section{Correspondence Detail:}

Dewi Nur Fiana

E-mail: dewinurfiana@gmail.com 


\section{INTRODUCTION}

Coronary artery bypass surgery is one of the intervention treatments of coronary artery disease. Based on data from the American Heart Association, a total of 427,000 coronary artery bypass surgeries were performed in the United States in 2004 and made this procedure the most common primary operation. ${ }^{1}$ Cardiac rehabilitation is an interdisciplinary approach to patients with limited function due to heart disease. The focus of cardiac rehabilitation was restored the patients function to optimal conditions of medical, physical, mental, psychological, social, emotional, sexual, vocational and economic status according to the degree of severity of heart disease experienced. ${ }^{2}$ The aim of Cardiac rehabilitation was to improve physical fitness, quality of life and reduced death from heart attack. ${ }^{3,4}$

Lower extremity muscle strength (LEMS) examined by conducting chair standing test The chair stand test $(\mathrm{CST})^{1}$ was one of the physical performance tests for older people and associated with muscle strength around the knee. The CST was assessed muscle strength around the knee joint in older people in the clinical setting without a hand-held dynamometer. The 30 Second CST, in conjunction with another measurement such as the 4-Stage Balance Test, Timed Up and Go (TUG) Test and an assessment of postural hypotension can be used to predict the risk of fall. ${ }^{5}$ The functional capacity evaluated by a simple 6-minute walking test (6 MWT), requires as long as 100-feet of the hallway, no need of the exercise equipment, nor specific training for the examiner. This test measures the distance that a patient can walk as fast as possible on a flat, hard surface for 6 minutes. The test evaluates the global and integrated responses of all the systems involved during exercise; the pulmonary and cardiovascular, circulation, neuromuscular units, and muscle metabolism.

Nevertheless, the test has not provided specific information about the different organs and systems that involved in exercise activity. The self-paced 6MWT assessed the submaximal level of functional capacity. Most patients do not achieve maximal exercise capacity during the 6 minutes, and choose their intensity of exercise and were allowed to stop and rest during the test. However, because most activities of daily living performed at submaximal levels of exertion, the 6MWD may better reflect the functional exercise level for daily physical activities. ${ }^{6}$

The effectiveness of the exercise depends on the optimal time and the intensity of exercise. Physiological response to exercise was the pattern depending on the state of health of an individual. The pattern called by the compensation cycle.

The optimal time to do the exercise was in the adaptation phase of the cycle after CABG, which is 36-72 hours after the previous exercise. ${ }^{7}$ The phase II of cardiac rehabilitation performed with a frequency of three times/ week. The supervised rehabilitation of the second phase of the heart with a frequency of three times/ weekwas increased the lower extremity muscle strength and functional capacity of post CABG patient. In contrast, a study of the frequency of two times/week was still limited. ${ }^{8-10}$ 
This study aimed to found the difference of frequency between two times/week and three times/week in phase II of supervised exercise in post CABG patients, on the effect of increasing lower extremity muscle strength and functional capacity.

\section{METHODS}

This experimental study was reviewed and approved by the research and ethics review committee of Medical Faculty, University of Padjadjaran, Bandung, Indonesia. All of the research was signed the informed consent before participating in the study.

A randomized controlled trial selected the subjects. The observations were at before and after exercises. The first of Statistical analysis was a test of normality of data Descriptive statistics, and frequency tables for category or rank data, Difference test by t-test or Mann Whitney test depends on the distribution of data to compare the difference of exercise frequency at the same exercise time (after four weeks). moreover, T-test dependent (pairwise) or Wilcoxson Match Pair test to assess exercise Fogress (start and end of week 4)

The inclusion criteria of the study were coronary artery disease patients who have undergone revascularization by a method of coronary artery bypass surgery (CABG), entering phase II cardiac rehabilitation, the absence of uncontrolled comorbid factors (Hypertension and Diabetes Mellitus, subjects do not have any neuromusculoskeletal comorbidities that participation in exercise and not use gait aid.

Exclusion criteria of the study have contraindicated for a 6-minute walking test, and cardiopulmonary exercise subjects have the severe chronic obstructive pulmonary disease, included in the high-risk category of exercise.

Drop Out Criteria were subject does not exercise in supervision according to the frequency specified more than once of absent and subjects who had experienced adverse effect during exercise.

A total of 30 subjects fulfilled inclusion and exclusion criteria, randomly allocated as many as 15 people to the group I (a group who received two times/week supervised exercise for four weeks) and 15 people to group II supervised exercise $3 \mathrm{x} /$ week for four weeks). Every participant was recommended to do overground walking hospital base exercise.

A total of 7 patients dropped out so that only 23 participants were able to complete the research (11 people in the group I and 12 people in group II). Lower extremity muscle strength obtained by conducting chair standing test, while functional capacity value obtained by conducting a 6-minute walking test. (Diagram 1) 


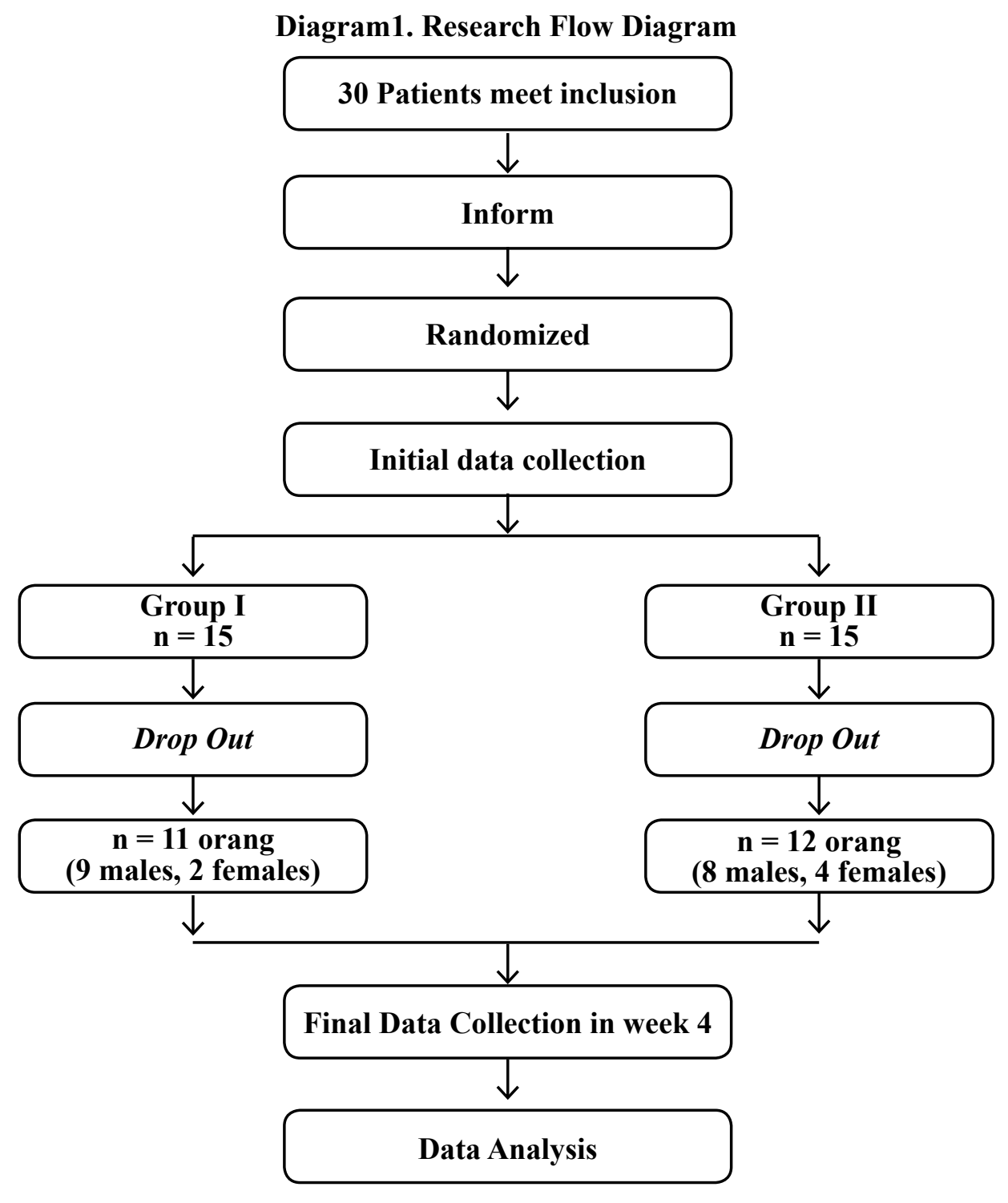

\section{RESULTS}

The result of the normality test by using Shapiro shows the value of participants data concerning normal age. The baseline data and the number of gender variation in the study subjects in both groups were not significantly different have described in Table 1.

Table 1. Participant's Characteristics at Baseline

\begin{tabular}{lrrr}
\hline & Group 1 & Group II & p-value \\
\hline Age (Year) & $58,54 \pm 5,90$ & $61,66 \pm 6,36$ & 0,317 \\
\hline Gender & & & 0,4085 \\
\hline Males & 9 & 8 & \\
\hline Females & 2 & 4 & \\
\hline
\end{tabular}

$1=$ frequency supervised exercise 2 times/week, $2=$ frequency supervised exercise 3 times/week 
The test of gender variation on functional capacity and lower extremity muscle strength has done by independent $\mathrm{t}$-test. The $\mathrm{p}$-value indicates the number of gender to functional capacity and lower extremity muscle strength did not differ significantly. Based on Table 2, the analysis of functional capacity and lower extremity muscle strength between groups can be performed as a whole, without separating the gender.

Table 2. The Functional Capacity and The Muscle Strength of Lower extremity based on gender

\begin{tabular}{ccccc}
\hline Variable & Mean & Mean & & \\
\hline & F & M & t-value & p-value \\
\hline Functional Capacity & 10,425 & 10,20 & 0,193905 & 0,848 \\
\hline Lower limb muscle strength & 8 & 8,35 & $-0,33418$ & 0,742 \\
\hline
\end{tabular}

F: Females; M: Males

Initial data on functional capacity and lower extremity muscle strength of group 1 and group 2 have shown in Table 3. The functional capacity and strength of lower limb muscles of both groups were statistically not significantly different due to $\mathrm{p}>0.05$.

Table 3 Initial Data of Functional Capacity and Lower Limb Muscle Strength

\begin{tabular}{cccc}
\hline & $\begin{array}{c}\text { Group I } \\
\text { Mean/Median* }\end{array}$ & $\begin{array}{c}\text { Group II } \\
\text { Mean/Median* }\end{array}$ & p-value \\
\hline Functional Capacity & $10,98 \pm 2,57$ & $9,60 \pm 2,02$ & 0,165 \\
\hline Lower limb muscle strength & $7,818 \pm 2,48$ & $8(5-11)^{*}$ & $0,186^{* *}$ \\
\hline
\end{tabular}

* Median (min-max)

** Mann Whitney test

Functional capacity and muscle strength before and after exercise different significantly with $\mathrm{p}<0.05$. The value of functional capacity in group I before exercise (10.98) was smaller than the value after exercise $(15,96)$. In group 2 , there was an increase in functional capacity before exercise $(9,60)$ and after exercise $(14,935)$. List of the data from Table 4 has described the increase of lower extremity muscle strength. The group I has the strength of lower limb muscles before the exercise of 7.818 increased to 12.909. In group II the baseline strength value of the lower limb 8.667 after exercise increased to 13.0.

Table 4. Functional Capacity and Muscle Strength Before and After the Exercise for 4 Week

\begin{tabular}{ccccccc}
\hline & \multicolumn{2}{c}{ Group I } & \multirow{2}{*}{ P-value } & \multicolumn{2}{c}{ Group II } & \multirow{2}{*}{ P-value } \\
\cline { 2 - 3 } \cline { 5 - 6 } & before & after & & before & after & \\
\hline Functional capacity & 10,9 & 15,9 & $<0,001$ & 9,6 & 14,9 & $<0,001$ \\
\hline $\begin{array}{c}\text { Lower Limb Muscle } \\
\text { Strength }\end{array}$ & 7,8 & 12,9 & $<0,001^{*}$ & 8,7 & 13,0 & $<0,001^{*}$ \\
\hline
\end{tabular}

Explanation: * Wilcoxon Matched Pairs Test due to abnormal distribution, others wear a paired UTI $t$ due to a normal distribution $\mathrm{I}=$ frequency supervised exercise $2 \mathrm{x} /$ week; $\mathrm{II}=$ frequency supervised exercise $3 \mathrm{x} /$ week 
Functional capacity and lower extremity muscle strength were not significantly different between groups after treatment, because of the $p>0,05$. The data in Table 5 has shown that was not different between groups.

Table 5. Functional Capacity and Lower Limb Muscle Strength between Groups 1 and 2 After Intervention For 4 Week

\begin{tabular}{cccc}
\hline & \multicolumn{2}{c}{$\begin{array}{c}\text { Group 1 } \\
\text { Mean 1/ }\end{array}$} & $\begin{array}{c}\text { Group II } \\
\text { Mean 2/ }\end{array}$ \\
\cline { 2 - 4 } & Median 1* & Median 2* & p-value \\
\hline Functional capacity & $15,96 \pm 2,94$ & $14,935 \pm 3,01$ & 0,717 \\
\hline Lower Limb Muscle Strength & $12(11-18)^{*}$ & $13,000 \pm 2,76$ & $0,782^{* *}$ \\
\hline
\end{tabular}

Explanation

* Median (min-max) due to abnormal distribution, others use mean \pm SD for normal distribution

** Man Whitney-t es $t$

** t-te st

\section{DISCUSSION}

An increase in functional capacity and lower extremity muscle strength after treatment found on both groups. Increased of the functional capacity post-cardiac rehabilitation phase II according to the study in 1995 by Dressendrofer et al. and in 2014 by Fimasari.

Dressendrofer et al. has found that cardiac rehabilitation between the frequency of two times/week and three times/week in myocardial infarction was equally effective in increasing pulmonary functional capacity. Dressendofer studies performed in myocardial infarction who did not undergo revascularization. ${ }^{11}$

Dressendrofer's and Fimasari have found that the functional capacity of patients on phase II cardiac rehabilitation increased significantly. Fimasari study was compared between cardiac rehabilitation group and not undergo exercise group, have found significant improvement in functional capacity in cardiac rehabilitation group. ${ }^{12}$

Functional capacity of this study obtained from the conversion of the maximum oxygen volume. The maximum oxygen volume was determined the respiratory and cardiovascular function on oxygen delivery to the contraction muscle, and the maximum ability of muscles to consume oxygen. ${ }^{13}$ The functional capacity after the intervention was higher than the before the exercise. The same condition on lower extremity muscle strength after exercise. The increase occurred in both intervention groups.

The physiological response of the exercise follows a cycle that occurs in healthy or sick individuals, called super-compensation cycles. Ideally, an exercise session should be carried out in the adaptation phase of one cycle of super-compensation. The adaptation phase lasts from 36 to 72 hours. ${ }^{7}$ In most studies of cardiac rehabilitation, and it generally has a frequency of three times/week (36-hour adaptation phase $\mathrm{e}^{6,8,9,14}$ 
Physiological changes in this phase include the addition of muscle mass, strength, mitochondrial density, aerobic enzyme activity, and nutrient storage capacity. ${ }^{9}$

The Group I performed a supervised exercise with a frequency of two times/week, assuming the exercise performed in a 72-96-hour elongation adaptation phase. The Group II performed a supervised exercise with a frequency of three times/week, assuming the exercise performed in a 36-hour adaptation phase. Table 4 the adaptation phase that occurs in participants occurred starting from 36 hours and can extend up to 96 hours.

\section{CONCLUSIONS}

The Differences of frequency (two times/week and three times/week) on supervised exercises for phase II cardiac rehabilitation have the same effect after four weeks exercises on increasing of the lower extremity muscle strength and the functional capacity in patients after coronary artery bypass graft.

\section{REFERENCES}

1. Rexius d. A simple score to assess mortality risk in patients waiting for coronary artery bypass grafting. Ann Thorac Surg 2006;81(2):577-82.

2. Jonathan H. Whiteson d. Cardiac Rehabilitation. In: Braddom RL, editor. Physical Medicine and Rehabilitation. 4 ed. Philadelphia: Saunders; 2007. p. 713-36.

3. Higgins HC. Rehabilitation outcomes following percutaneous coronary interventions (PCI). Patient education and counseling. 2001;43(3):219-30.

4. Chludilová d. Functional capacity in men after coronary artery bypass surgery influenced by physical training. Scripta Medica (Brno). 2007;80(5):203-10.

5. Zhang F, Ferrucci L, Culham E, et al. : Performance on five times sit-to-stand task as a predictor of subsequent falls and disability in older persons. J Aging Health, 2013, 25: 478-492.

6. ATS Statement: Guidelines for the Six-Minute Walk Test :MARCH 2002

7. Perk J, Gohlke H, Hellemans I, Mathes $\mathrm{P}, \mathrm{McGee} \mathrm{H}$, Monpère C, et al. Cardiovascular prevention and rehabilitation.Springer;2007.

8. Nazari N. Effect of Cardiac Rehabilitation on Strength and Balance in Patients after Coronary Artery Bypass Graft (CABG). نادهاز عكشزب مولع تاقىقحت ملجم 2014;16(1):74-8.

9. Dolansky MA, Moore SM. Effects of cardiac rehabilitation on the recovery outcomes of older adults after coronary artery bypass surgery. JCRP. 2004;24(4):236-44.

10. Braddom RL. Physical medicine and rehabilitation.Elsevier Health Sciences;2010.

11. Rocha, LY.1, Caperuto, EC.1, Irigoyen, MC.2 and Rodrigues B.1Impact of exercise training and 
detraining after myocardial infarction: a literature review Barboza, Human Movement Laboratory, São Judas University.2012

12. Ragawanti P. Effect Of Cardiac Rehabilitation Programs On Functional Capacity Of Post Coronary Revascularization Patient Using Six Minute Walk-Test. Folia Medica Indonesiana. 2014;50(2):86-91.

13. Battinelli T. Aerobic and anaerobic conditioning. Physique, fitness, and performance. Florida: CRC Press; 2000.

14. Physicians SERCO. Cardiac Rehabilitation A National Clinical Guideline. Edinburgh: Scottish Intercollegiate Guideline Network;2002. 